\title{
Survival Analysis of the Clinical Episodes of Stroke Using Data from Western Delta Region of Nigeria
}

\author{
$\underline{\text { K. I. Ekerikevwe }}$ \\ Department of Statistics, School of Applied Sciences \& Technology, Delta State Polytechnic, Otefe- \\ Oghara, P.M.B. 03, Oghara, Delta State, Nigeria \\ Email: kennedyekerikevwe@gmail.com
}

\begin{abstract}
:
This study is designed to investigate the epidemiology of stroke burden in Western Delta Region of Nigeria. To achieve this, statistical tools were used to analyze and interpret the prevalence of this diseases in the study area-with focus on the medical records (case files) of hundred and twenty-one (221) patients who suffered from stroke and were seen at selected government hospitals in the region, from 2003-2016. The clinical episodes (CEs) of stroke for the patients who were admitted during acute care period (without discharge against medical advice) and were then assessed for various investigations and treatment interventions and long term care were obtained and statistically studied. The Kaplan-Meier survival estimator shows the survival rate to be $75 \%$ in 2003 and $25 \%$ in 2016. The year 2009 recorded the highest CEs (28) with survival function (0.23) and 2014 the lowest (4) with survival function (0.11). These have implications for all stakeholders in health matters in the study area. The study recommends an organized effort from both the government and the private sector to tackle the rising stroke burden in Western Delta Region of Nigeria.
\end{abstract}

Keywords:

clinical; survival; cerebrovascular; prevalence; stroke; health; burden; accident

\section{Introduction}

Stroke, known in medical terms as Cerebrovascular Accident (CVA), is one of the leading causes of morbidity and mortality around the world and it imposes enormous economic burden on individuals and society. A stroke is when the blood flow to a part of a person's brain is stopped either by a blockage or by the rupture of a blood vessel. Stroke is a global epidemic, and hence, it is not limiting to developed or developing economies alone, it cut across all nations across the globe. Its emergence in developing countries like Nigeria creates a burden for concern. Stroke is a costly disease from human, family, and societal perspectives. Available facts and figures may easily explain why the economic burden of stroke is requiring increasing attention for more effective health care planning, implementation and resources allocation. Stroke is a problem that occurs in the brain. It occurs when there is no blood supply to a part of the brain which makes that part of the brain suffer. It means therefore that whatever functions that part of the brain does, stops. Effective stroke mortality data reporting is an important measure, which will increase the chances of knowledge on the epidemiology of stroke in a society and help in its reduction. Data on stroke mortality are therefore important for monitoring the disease trend and aide health institutions in planning public health interventions. The knowledge acquired in this study concerning the survival of stroke will be of use in the management of patients. This will lead to a reduction in stroke mortality and further disability. Many health practitioners have suggested that some of the major causes of stroke include cigarette smoking, cocaine use, or drinking too much alcohol, presence of diabetes (high blood sugar), atherosclerosis (hardening of the arteries) or fatty cholesterol deposits on artery walls, heart disease, such as coronary artery disease, high blood cholesterol (fat) and high blood pressure. 
According the report of the European Cardiovascular Disease Statistics (2008), in 27 European Union countries, total annual cost of stroke is estimated at $€ 27$ billion: $€ 18.5$ billion $(68.5 \%)$ for direct and $€ 8.5$ billion $(31.5 \%)$ for indirect costs. A further sum of $€ 11.1$ billion is calculated for the value of informal care. To Beth (2003) stroke is one of the major public health problems in the world today. It is the third leading cause of death worldwide after ischaemic heart disease and cancer. Most of these stroke deaths are found in the developing countries. The deaths in these countries account for as much as $87 \%$ of all the stroke deaths. This high death toll is even more in Sub Saharan Africa. Nigeria, the country where this study was carried out is a sub Saharan African country.

\section{Review of Literature}

Kaseem (2007) carried out a study on the causes and complication of stroke and he noted that mortality rate from stroke attack in Nigeria are very high, with a range of $21 \%-45 \%$. He added that it is worthy of note that most of the dead patients in the Nigerian studies died within the acute phase. He concluded that the morbidity and mortality after stroke have been shown to arise from complications and that post-stroke complication is a leading cause of death accounting for $23-50 \%$ of total deaths in patients with ischaemic stroke.

Yan et al (2013) studied five year post-stroke survival and rehospitalization due to stroke recurrence as well as their associations with patient demographics for different stroke types in Singapore. The causes for post-stroke mortality and the recurrent stroke types were also studied. Specific preventive strategies are needed to target the high risk groups to improve their long-term outcomes after acute stroke. Mandip et al (2016) in their large population-based study, South Asian diabetic stroke patients had higher recurrent stroke rates compared to non-South Asians, despite a younger age profile. On the side of Gregor (2015) who conducted a study on the predictors of stroke in Cape Town found that predictors of stroke mortality are related to old age. The study indicated that older age (age $>60$ years) has been shown to be a predictor of mortality. He also examined the effect of sex on the prevalence of stroke and the study revealed that the effect of sex on the outcome of stroke is varied. Raphael et al, (2007) developed a model on stroke. In their model, they considered a macroscopic level with a cell population scale. Thus, they used ordinary and partial differential equations to describe inflammation of stroke. The model reproduces the inflammatory process during the first 72 hours of the stroke. Every function depends on the time $t$ and on the space $\mathrm{x}$.

Nanda Aulia Yusuf Purba, Humairi and Kariono (2019) examined the social and public health impact that occurred in rantau utara subdistrict after the publication of Labubanbatu district regulations about the swallow bird tax. The method of this study is qualitative research by using interview data to local government and society. The result of this study there has been no social impact found in the District of Rantau Utara and Rantau Selatan Subdistrict Labubanbatu Regency since Regional Regulation Number 10 of 2011 concerning Taxes for Swallow Bird Nests imposed. Zulkarnain (2019) studies the eradication efforts of drug abuse in Indonesia. The subject of this study is drug abuse in the perspective of Islamic Law based on revelation and in the perspective of Indonesian positive law. The approach used in this study is comparative through juridical normativetelogic. The result shows that the concept of prevention and tackling of drugs in Islamic law in the form of preventive, refresive and educative. Whereas in Indonesian positive law through law No. 35 of 2009 in the form of preventive, refresive, curative and educative efforts and has made compulsory provisions for the rehabilitation of addicts and victims of drug abuse. Benjamin Gbolo Zoawe (2019) assesses the clinical efficacy of an improved traditional medicine called Drepanoalpha (an anti-sickle cell polyherbal formula) in a bomozygous sickle patient using the quantum magnetic resonance analyzer. The results show the relevance of the use of this unconventional technical approach in the sickle cell disease patient treatment evaluation. Indeed, this study showed that 
Drepanoalpha is effective in vivo and restored homeostatic balance by optimizing some vital functions in the treated patient. The quantum magnetic resonance analyzer is therefore an important away which allows understanding the disorders of the body due to sickle cell disease and their correction post-treatment. They opined that it is desirable that the use of this device be validated in the evaluation of the effectiveness of anti-sickling drugs in large-scale clinical trials in rural areas like Nord-Ubangi province. They concluded that, Indeed, this instrument is not only fast, practical, economical, accessible, non-invasive but also easy to use and suitable for this category of research in underprivileged areas. The results obtained are in perfect agreement with the facts observed (recovery of some vital parameters and disappearance of seizures in the patient). Morteza et al (2015) conducted a retrospective cohort study on 529 Iranian females with BC underwent surgery, from 1995 to 2013. Patients, tumor and treatment characteristics were collected from medical records of the patients. The illness-death model was used to investigate the relationship between these factors and survival time. Data were analyzed using version 3.1 .1 of $\mathrm{R}$ software. Their results show the risk of FRT in patients who had tumors size in the range of $2-5 \mathrm{~cm}$ and $>5 \mathrm{~cm}$ was 1.3 and 3.5 times higher than that of patients with tumor size $\leq 2 \mathrm{~cm}$, respectively $(P<0.001)$. Furthermore, risk of death in patients aged $\geq 50$ years was 1.6 times higher compared to patients aged less than 50 years $(P=0.012)$. Risk of death after metastasis in patients with tumor size $>5 \mathrm{~cm}$ was 2.1 times higher than patients with tumor size $\leq 2 \mathrm{~cm}(P=0.019)$.

Alireza (2014) conducted a survey on 15830 women diagnosed with breast cancer in British Columbia, Canada. They were divided into eight groups according to patients' ages and stage of disease Either Cox's PH model or stratified Cox model was fitted to each group according to the PH assumption and tested using Schoenfeld residuals. The data show that in the group of patients under age 50 years old and over age 50 with stage I cancer, the highest hazard was related to radiotherapy (HR=3.15, CI: 1.85-5.35) and chemotherapy (HR=3, CI: 2.29- 3.93) respectively. For both groups of patients with stage II cancer, the highest risk was related to radiotherapy ( $\mathrm{HR}=3.02$, CI: 2.26-4.03) ( $\mathrm{HR}=2.16$, CI:1.85-2.52). For both groups of patients with stage III cancer, the highest risk was for surgery ( $\mathrm{HR}=0.49$, CI: 0.33-0.73), (HR=0.45, CI: 0.360.57). For patients of age 50 years or less with stage IV cancer, none of the treatments were statistically significant. In group of patients over age 50 years old with stage IV cancer, the highest hazard was related to surgery (HR=0.64, CI: 0.53-0.78).

Barton et al (2009), in their paper present results of survival analysis that utilise length of stay and destination as outcome measures, based on data from the Belfast City Hospital. Survival probabilities were determined using Kaplan-Meier survival curves and log rank tests. Multivariate Cox proportional hazards models were also fitted to identify independent predictors of length of stay including age, gender and diagnosis. Elderly patients showed a decreased hazard ratio of discharge. However, gender was not a significant hazard risk for length of stay in hospital. Those patients with a diagnosis of cerebral haemorrhage showed an increased hazard ratio and hence were most likely to have a shorter length of stay and to die in hospital. Those who were eventually discharged to a Private Nursing Home had the lowest probability of early discharge. On the basis of these results we have created several groups, stratified by age, gender diagnosis and destination. These groups are then used to form the basis of a simulation model where each group is a patient pathway within the simulation. Various scenarios are explored with a particular focus on the potential efficiency gains if length of stay in hospital, prior to discharge to a Private Nursing Home, can be reduced. Deljavan et al (2018) carried out a study to determine the inhospital survival of patients referred to the 2 stroke centers in North-West of Iran during a full seasonal year from April 2015.All the consecutive patients with stroke admitted to the 2 main stroke centers at Tabriz (Imam Reza University Hospital and Razi University Hospital) were recruited in this study. Stroke patients from both ischemic and hemorrhagic subtypes were selected based on the registry data and International Classification of Diseases, 10th edition. At admission, details of examination including vital signs, neurologic and systemic examination. 
Modified Rankin Scale, and Glasgow Coma Scale were recorded. Baseline hematological and biochemical parameter assessments as well as computerized tomographic scanning were conducted. Cox regression was used to investigate and detect potential predictors of in-hospital survival. A total of 1,990 patients with stroke were studied. Males comprised $52.1 \%(1,036)$ of the subjects. The mean age of the patients was 65.8 years. Three hundred and fifty-seven $(17.9 \%)$ patients had hemorrhagic stroke vs 1,633 (82.1\%) with ischemic stroke. In-hospital case-fatality proportion was 12.5\% (95\% CI: 11.1-14). Based on modified Rankin Scale score at admission, 1,377 of 1,990 patients $(69.2 \%$ ) had a poor outcome (modified Rankin Scale score $\geq 3$ ) at the admission time. The regression analysis showed that at least 7 variables could independently predict hospital survival of patients with stroke including age $\geq 65$ years, higher admission modified Rankin Scale score, lower admission Glasgow Coma Scale score, hemorrhagic stroke nature, diabetes, having valvular heart disease, and having aspiration pneumonia. The study concluded that the case-fatality of stroke in the present study setting is high and needs to be appropriately addressed through prevention or management of some of these factors such as diabetes, pneumonia, and valvular heart diseases.

On the face of determining the management and prevention of stroke, Adebuyi (2000), stated that stroke is not curable but it is manageable. He stated that stroke is treatable but it is not curable in the sense that if somebody has had one stroke, they can have another one. For us in Nigeria, the most important treatment is prevention. We have to do whatever we can to prevent people from having stroke; which means we need to inform people out there on what causes stroke. Stroke is common in Nigeria. It is on the increase in Nigeria and it is something that most Nigerians, perhaps, they know little about the real problem and the magnitude of the problem. Stroke is either the third or fourth killer disease and it is a major cause of disability in Nigeria today. It is a big issue; it is a big problem. Hence, this study was motivated by the ugly reoccurrence of the CVA amongst the people in the society and the provision of monitoring model for the spread. This study was seeks to achieve the following objectives:

- To identify the possible causes and preventive measures of stroke

- To establish a survival function for the epidemiology of stroke in Western Delta Region of Nigeria

\section{Research Method}

Survival analysis can be explained as a set of methods for analyzing data where the outcome variable is the time until the occurrence of an event of interest. The event can be death, occurrence of a disease, marriage, divorce, etc. In this study, the event of interest is on the attack and death of stroke. The time to event or survival time can be measured in days, weeks, years, etc. In survival analysis, subjects are usually followed over a specified time period and the focus is on the time at which the event of interest occurs and in this study, the focus of time is in years (2003 - 2016). A survival function was modeled in this study and a survival function is the probability that a patient, with stroke attack will survive beyond a specified time.

Survival function for the first period

Survival function for the first period $=1-\frac{\text { numbar of avent }}{\text { total numbar of patiants }}$ 


\section{But for time 2 and above \\ $\left(1-\frac{\text { number of event }}{\text { total number of patients }}\right) \times$ previous suvival rate}

According to Kaplan (1958), the Kaplan-Meier (K-M) method or product limit method is a statistical technique used to analyze cancer data. It is applied in analyzing the distribution of the patient's survival times following their recruitment into the study. The analysis expresses this in terms of proportion of patients still alive up to a given time following the recruitment or entry into the study. The K-M estimator is also called nonparametric maximum likelihood estimator. It is used for estimating survival probabilities. The method computes the probability of dying at a certain point in time conditional to the survival, up to that point. It utilizes the information of censored individuals till the point when the patient is censored. Thus, it maximizes utilization of available information on time to event of the study sample. This is a modified form of the 'Life Table' technique, with the condition that each time interval contains exactly one event, and event occurs at the beginning of the time interval. In clinical studies, individual data are usually available on time to death or time to last seen alive. The life table technique is one of the oldest methods for analyzing survival data.

The Kaplan-Meier estimator also called the product limit estimator; a nonparametric statistic used to estimate the survival function from a set of lifetime data. The function estimates the survival rates and hazard from data that may be either complete or incomplete. The function of the survival rate is given as:

$S(t)=\frac{\text { number of individuals surving langer than time } t}{\text { total number of individuals studied }}$

In the function above, $\mathrm{t}$ is a time period known as the survival time. $\mathrm{S}$ represents the estimated probability of surviving at time $\mathrm{t}$ for those alive. At $\mathrm{t}=0, \mathrm{~S}(\mathrm{t})=1$ and decreases towards 0 as $t$ increases towards infinity $(\infty)$.

$\hat{S}=\prod_{t_{i} \leq t}^{\infty}\left[1-\frac{a_{i}}{n_{i}}\right]$

The product limit method of Kaplan-Meier estimator is used to estimate S.

Where $t_{i}$ denotes the duration of study at point $i, d_{i}$ is the number of deaths up to point $i$ and $n_{i}$ is the number of individuals at risk just before $t_{i}$. $S$ is based upon the probability that an individual survives at the end of a time interval, on the condition that the individual was present at the start of the time interval. While the Kaplan-Meier estimator with log-rank test is useful for comparing survival curves in two or more groups, Cox regression (also called the proportional hazard function/regression) aide the analysis of the effects of several variables as risk factors of survival. The Cox proportional hazard model is a method of analyzing the effect of different risk factors on the hazard function. Assuming $\mathrm{n}$ individuals under observation, the Cox proportional hazard model is of the form

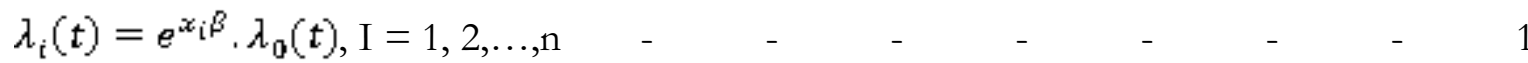

In which $x_{i}\left(x_{i 1}, x_{i 2}, \ldots, x_{i k}\right)$ is the vector covariate values for individual $i, \beta=\left(\beta_{1}, \beta_{2}, \ldots, \beta_{k}\right)^{1}$ is the vector of regression coefficients, $\lambda_{i}(t)$ is the hazard function of individual $i$ and $\lambda_{0}(t)$ is the baseline hazard. Thus, the baseline hazard corresponds to an observation with $\mathrm{x}_{\mathrm{i}}=0$. The effect of the risk factors on the hazard function in the Cox proportional hazard model does not depend on time because the ratio $\frac{\lambda_{i}(t)}{\lambda_{0}(t)}$ is equal to the constant $c_{i}$. Consequently, the baseline hazard determines the shape of the hazard function. The ratio of the hazard functions of individuals $i$ 
and $\mathrm{j}$, namely

$\frac{\lambda_{i}(t)}{\lambda_{j}(t)}$, is called the hazard ratio. This quotient is equal to

$\frac{\lambda_{i}(t)}{\lambda_{j}(t)}=\frac{e^{x_{i} \beta} \lambda_{0}(t)}{{ }^{x_{j} \beta} \cdot \lambda_{0}(t)}=e^{\left(x_{i}-x_{j}\right)^{1} \beta}$

\section{Result}

Table 1. Survival Function/Rate

\begin{tabular}{llccc}
\hline Time & $\begin{array}{l}\text { Number } \\
\text { of subjects }\end{array}$ & $\begin{array}{l}\text { Failure/event } \\
\text { (death during the } \\
\text { treatment period) }\end{array}$ & $\begin{array}{l}\text { Net } \\
\text { lost/censored }\end{array}$ & Survival function \\
\hline $\mathbf{1}$ & 16 & 4 & 3 & 0.75 \\
$\mathbf{2}$ & 12 & 1 & 9 & 0.69 \\
$\mathbf{3}$ & 9 & 2 & 7 & 0.54 \\
$\mathbf{4}$ & 21 & 4 & 12 & 0.44 \\
$\mathbf{5}$ & 14 & 2 & 10 & 0.38 \\
$\mathbf{6}$ & 19 & 4 & 19 & 0.30 \\
$\mathbf{7}$ & 28 & 7 & 18 & 0.23 \\
$\mathbf{8}$ & 20 & 1 & 15 & 0.22 \\
$\mathbf{9}$ & 14 & 5 & 6 & 0.14 \\
$\mathbf{1 0}$ & 17 & 2 & 15 & 0.12 \\
$\mathbf{1 1}$ & 8 & 1 & 7 & 0.11 \\
$\mathbf{1 2}$ & 4 & 0 & 1 & 0.11 \\
$\mathbf{1 3}$ & 23 & 5 & 9 & 0.09 \\
$\mathbf{1 4}$ & 16 & 0 & 12 & 0.09 \\
\hline
\end{tabular}

Table 2. Overall Model Comparison

Overall Comparisons

\begin{tabular}{lccc}
\hline & Chi-Square & Df & Sig. \\
Log Rank (Mantel-Cox) & 7.332 & 2 & 0.026
\end{tabular}

Test of equality of survival distributions for the different levels of number of subjects.

\begin{tabular}{|c|c|c|c|c|c|c|c|c|}
\hline \multicolumn{9}{|c|}{ Omnibus Tests of Model Coefficients ${ }^{a}$} \\
\hline \multirow[t]{2}{*}{$\begin{array}{lr}-2 & \text { Log } \\
\text { Likelihood }\end{array}$} & \multicolumn{3}{|c|}{ Overall (score) } & \multicolumn{2}{|c|}{ Change From Previous Step } & \multicolumn{2}{|c|}{$\begin{array}{l}\text { ChangeFrom } \\
\text { Block }\end{array}$} & \\
\hline & $\begin{array}{l}\text { Chi- } \\
\text { square }\end{array}$ & & Sig. & $\begin{array}{l}\text { Chi- } \\
\text { square }\end{array}$ & Sig. & $\begin{array}{l}\text { Chi- } \\
\text { square }\end{array}$ & & Sig. \\
\hline 23.173 & 7.332 & 2 & 0.026 & 10.97 & 0.004 & 10.97 & 2 & 0.004 \\
\hline
\end{tabular}




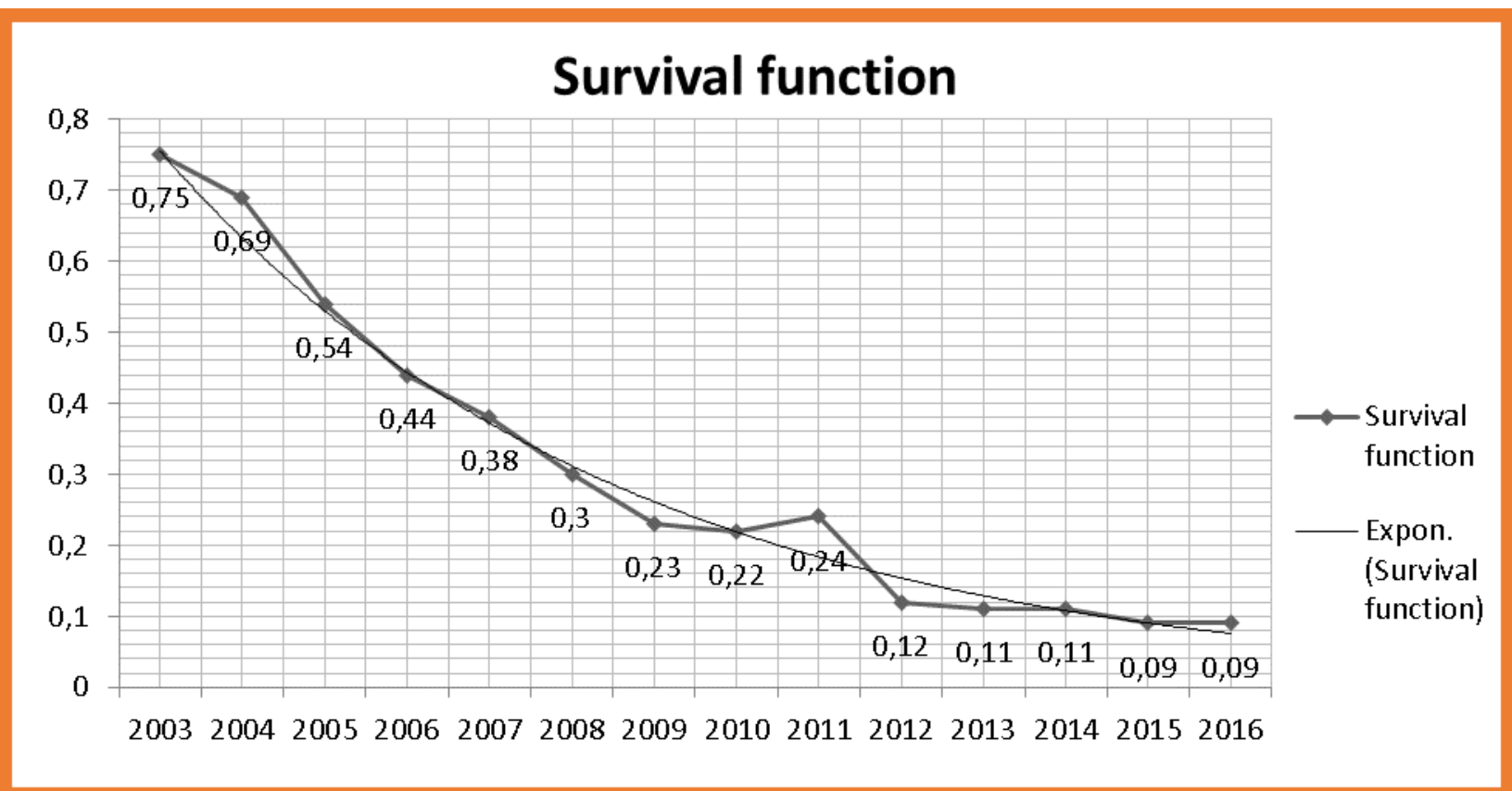

Figure 1. Survival function of stroke patients in Western Delta of Nigeria

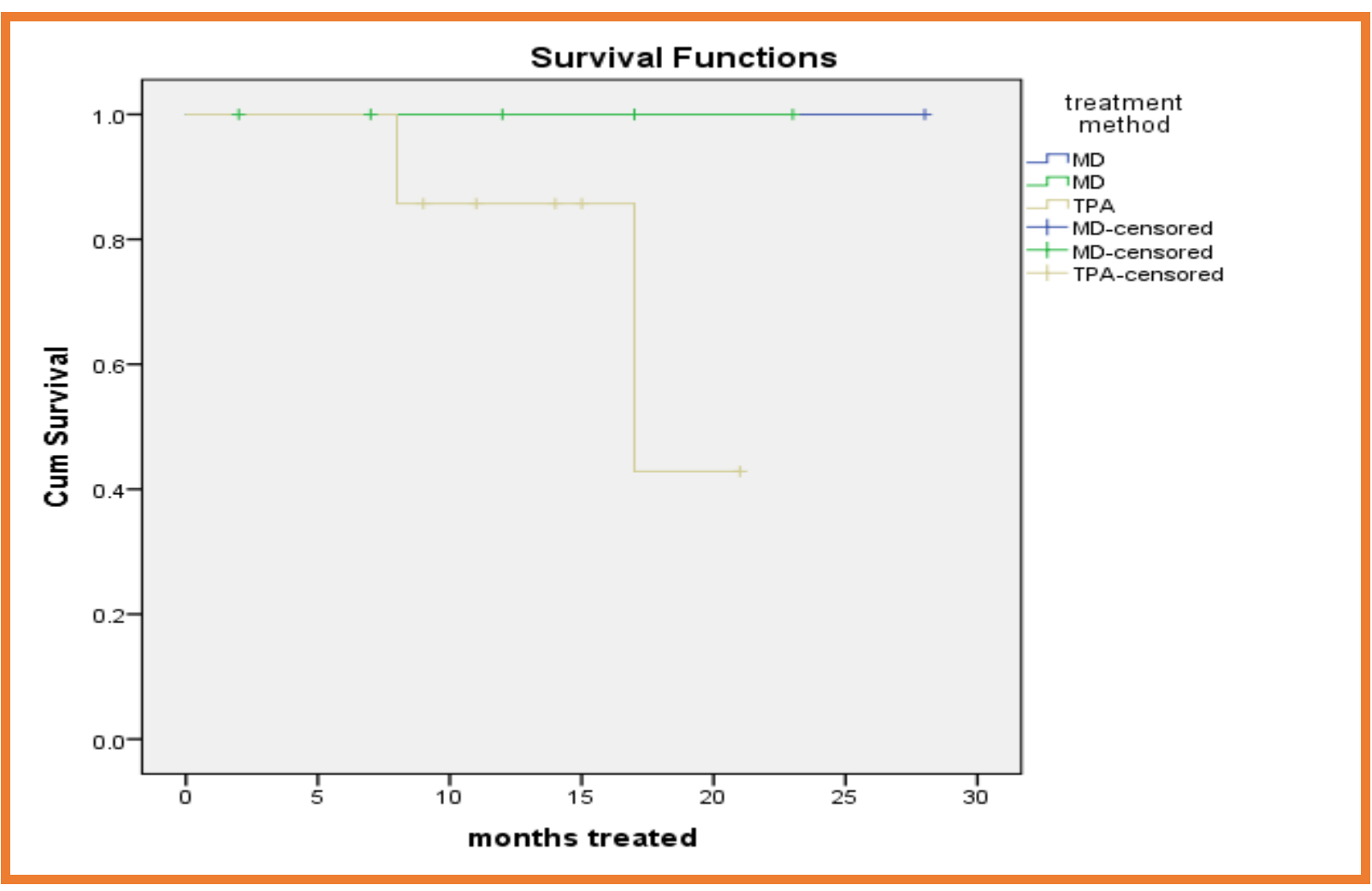

Figure 2. The survival function by Kaplan Meier 


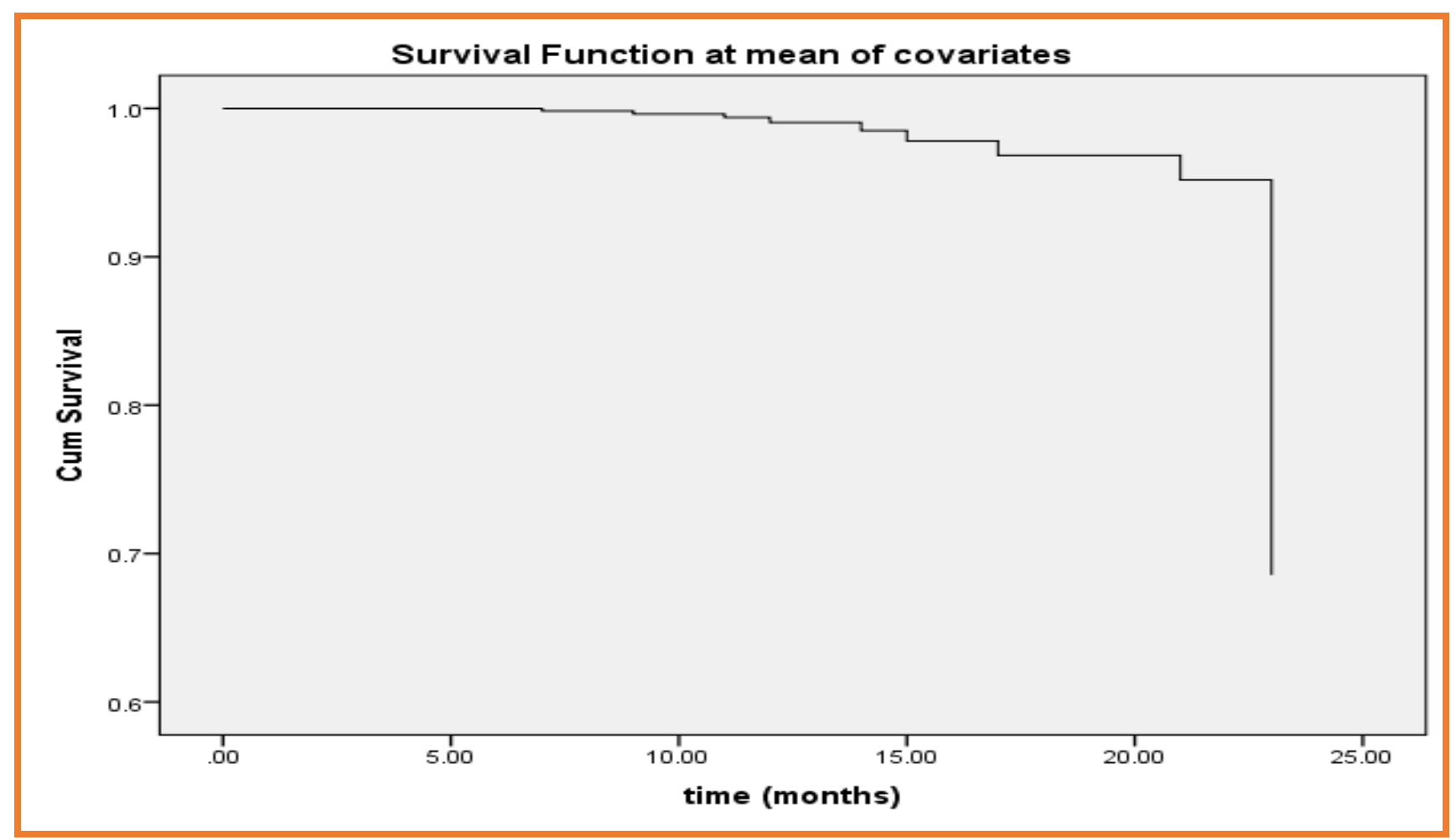

Figure 3. The survival function by Cox regression

\section{Kaplan Meier and Cox- Regression survivor Estimators}

Level of significance $=0.05$

Table 3. Summary of Test Statistic

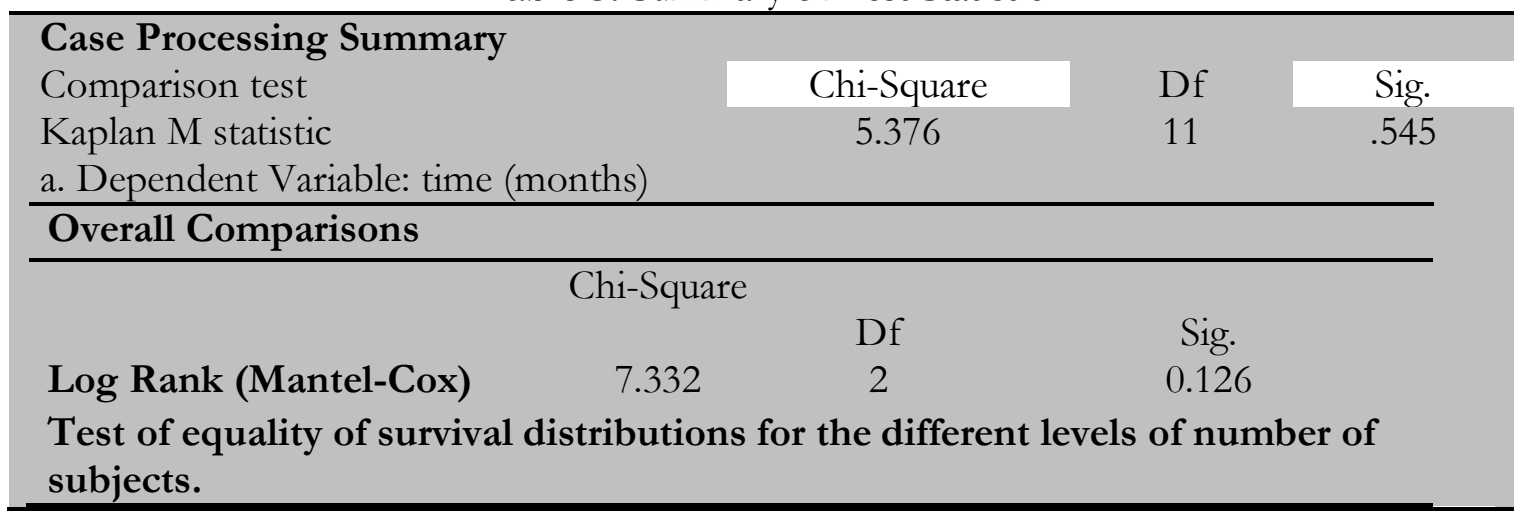

\section{Discussion}

From the analysis, Table I presents the survival functions of the clinical episode of selected stroke patients in the study region. The results show a downward (Decline) in the survival rate of people attacked by this disease for the period under study. This implies that there was a decline from 0.75 in 2003 to 0.09 in 2016. Table II shows that, the overall model comparisons test of equality of survival distributions for the different levels of number of subjects under consideration, to be statistically significant. Figure I show a continuously downward decline in survival rate of the patients; this collaborated the results in Table I. 


\section{Conclusion}

The main strengths of this study are that we have studied about $75 \%$ survival rate of the stroke population across multi-hospitals in Western Delta Region of Nigeria in 2003 and the survival rate fell to $9 \%$ in 2016. The causes for post-stroke mortality and the recurrent stroke types were also studied. Specific preventive strategies are needed to target the high risk groups to improve their long-term outcomes after acute stroke in this region. These have implications for all stakeholders in health matters in the study area. The study recommends an organized effort from both the government and the private sector to tackle the rising stroke burden in Western Delta Region of Nigeria.

\section{References}

Adebuyi, O. O. (2000) Effect of Urgent Treatment of Transient Ischaemic Attack and Minor Stroke on Early Recurrent Stroke: A Prospective Population-Based Sequential Comparison. Journal of Neural Science, Vol. 20

Alireza Abadi, Parvin Yavari, Monireh Dehghani-Arani, Hamid Alavi-Majd, Erfan Ghasemi, Farzaneh Amanpour, and Chris Bajdik (2014) Cox Models Survival Analysis Based on Breast Cancer Treatments. Iran J Cancer Prev. 2014 Summer;7(3): 124 129.

Barton, M., McClean, S. I., Garg, L., \& Fullerton, K. (2009). Modelling stroke patient pathways using survival analysis and simulation modelling. XIII International Conference on Applied Stochastic Models and Data Analysis, Vilnius. 370-373.

Beth, W. (2003) The Burden of Disease and Injury in Australia. Canberra. Australian Institute Of Health And Welfare, Bulletin.

Benjamin Gbolo Zoawe, Koto-te-Nyiwa Ngbolua, Pius T. Mpiana, Ndanga Bikibo Appolinaire, Pangodi Aundagba Jean-Marie, Masengo Ashande Colette, Mudogo Virima (2019) Evaluation of the Clinical Efficiency of an Antisickling Polyherbal Formula Drepanoalpha in a Sickle cell disease Patient in Gbado-Lite City (Democratic Republic of the Congo) by Quantum Magnetic Resonance Analyzer. Vol 1 No 1 (2019): Britain International of Exact Sciences Journal, September

Deljavan R, Farhoudi M, Sadeghi-Bazargani (2018) Stroke in-hospital survival and its predictors: the first results from Tabriz Stroke Registry of Iran. Int J Gen Med. 2018 Jun 19;11:233240. doi: 10.2147/IJGM.S158296

European Cardiovascular Disease Statistics (2008). Available at: http://www.ecds.org.uk/research spend-uk

Gregor, M. (2011) Scottish Stroke Care Audit, 2011 National Report. Available

http:// ww.strokeaudit.scot.nhs.uk/downloads/2011_National_Report.html

Kaplan EL, Meier PL. (1958) Non parametric estimation from incomplete observations. J Am Stat Assoc, 53:457-81.

Kaseem, U. (2007) Comparative Effectiveness of Exercise and Drug Interventions onOutcomes: Meta-epidemiological Study. Body Morphology Journal, vol. 12

Mandip S Dhamoon, Limei Zhou, Melissa Stamplecoski, Moira Kapral, Baiju Shah (2016) Stroke recurrence among South Asians with diabetes in Ontario, Canada First Published June 15, https://doi.org/10.1177/1747493016654488

Morteza Hajihosseini, Javad Faradmal," And Abdolazim Sadighi-Pashaki (2019) Survival Analysis of Breast Cancer Patients after Surgery with an Intermediate Event: Application of Illness- Death Model.Iran J Public Health. 2015 Dec; 44(12): 1677-1684.

Nanda Aulia Yusuf Purba, Humaizi and Kariono (2019) The Social and Public Health Impacts 
that Occurred in Rantau Utara Subdistrict after the Publication of the Labuhanbatu District Regulations No. 10 of 2011 About the Swallow Bird Tax, Indonesia. Britain International HumanitiesandSocialSciencesJournal,Vol1,No1JuneDOI: https://doi.org/10.33258/biarj ohs. v1i1.11

Rapheal, A., Zuba, F. O., Quazim, N. N. and Jane, O. J. (2007) Statistics on Smoking, England2007. Available: http://www.hscic.gov.uk/catalogue/232/smok-eng

Yan Sun, Sze Haur Lee, Bee Hoon Heng, and Vivien S Chin (2013) 5-year survival and rehospitalization due to stroke recurrence among patients with hemorrhagic or ischemic strokes in Singapore BMC Neurol. 2013; 13: 133.Published online 2013 Oct 3. doi: 10.1186/1471-2377-13-133

Zulkarnain (2019) Eradication Efforts of Drug Abuse in Indonesia. Britain International of Humanities and Social Sciences Journal, Vol 1 No 1 June DOI: https://doi.org/10.33258/biarjohs.v1i1.4 